\title{
The transition between a poroma and a porocarcinoma evidenced by the dermoscopy*
}

\author{
Juliana Uchiyamaํㅡㄹ Márcio Martins Lobo Jardim, Neusa Yuriko Sakai Valente ${ }^{1}$, Maria Fernanda Vieira \\ Cunha Camargo ${ }^{1}$
}

DOI: http:/ / dx.doi.org/10.1590/abd1806-4841.20197280

\begin{abstract}
Eccrine porocarcinoma (EPC) is a rare malignant skin tumor. The dermoscopy of invasive EPC reveals focal presence of whitish-pink, structureless areas surrounded by pinkish-white halos. In an eccrine poroma (EP), such areas present diffuse distribution in the "frog- eggs" pattern. We reported an EPC in situ that presents a transitional dermoscopy pattern between EP and invasive EPC. We found a diffuse distribution; whitish-pink, structureless areas surrounded by pinkish-white halos; a central exulceration and a polymorphic vascular pattern.
\end{abstract}

Keywords: Dermoscopy; Eccrine porocarcinoma; Poroma

\section{INTRODUCTION}

An eccrine porocarcinoma (EPC) is a rare, malignant cutaneous neoplasm that originates from the intraepidermal duct portion of the sweat gland. Dermoscopy is a non-invasive procedure used increasingly to facilitate clinical diagnosis. In this report, we describe a case of EPC in situ, the dermoscopy of which revealed a transitional pattern between an eccrine poroma and an invasive EPC.

\section{CASE REPORT}

An Asian, 70-year-old female patient complained of an erythematous papule on the right leg since infancy, reporting progressi- ve growth for about six months, without associated symptoms.

The clinical exam revealed a well-defined erythematous papule, approximately $8 \mathrm{~mm}$ in diameter, with a small central hematic crust, localized on the right leg, near the knee (Figure 1).

Dermoscopy of the lesion showed structureless, whitish-pink areas, surrounded by pinkish-white halos and distributed diffusely, with central exulceration and linear irregular vessels (Figure 2).

The hypotheses of amelanotic melanoma and pyogenic granuloma were proposed, and an excisional biopsy was performed.

The histopathology exam revealed an exophytic and endophytic lesion with clonal proliferation, restricted to the epidermis, of

Received 16 May 2017.

Accepted 01 February 2018.

* Work conducted at the Hospital do Servidor Estadual de São Paulo, São Paulo (SP), Brazil.

Financial support: None.

Conflict of interest: None.

1 Department of Dermatology, Hospital do Servidor Estadual de São Paulo, São Paulo (SP), Brazil.

MAILING AdDRESS:

Juliana Uchiyama

E-mail: juliana.uchiyama@gmail.com

@ 2019 by Anais Brasileiros de Dermatologia

(cc) BY-NC 
squamous and basal cells, some with atypia, interspersed with areas of ductal differentiation (Figures 3, 4 and 5). Thus, we determined this lesion to be an eccrine porocarcinoma in situ.

The patient continued out-patient follow-up for eight months, without relapse of the lesion to date.

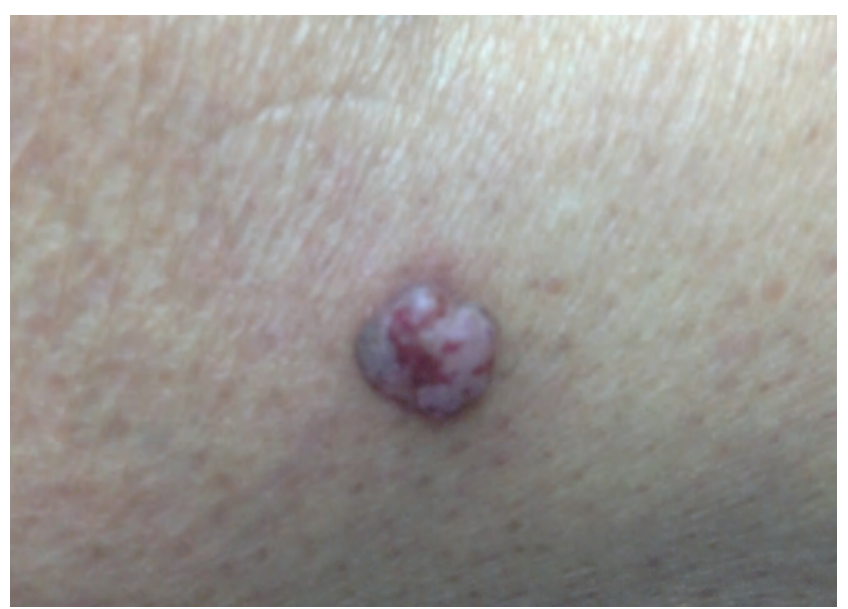

Figure 1: Well-defined erythematous papule with smooth surface and central exulceration
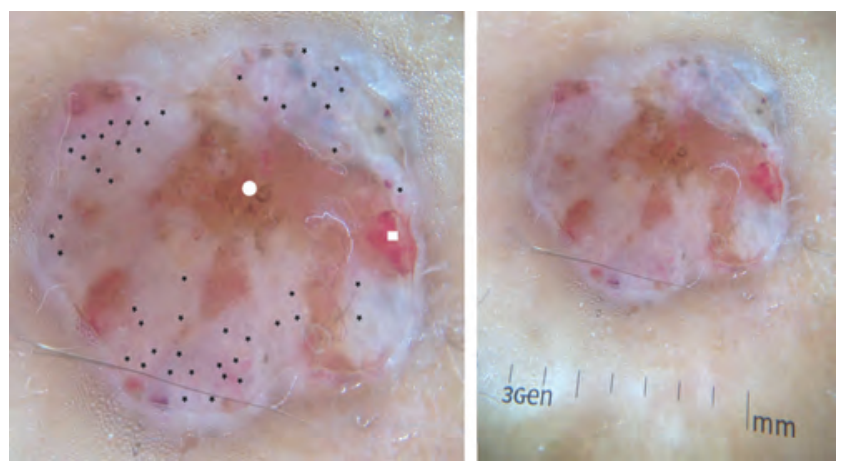

FiguRE 2: Dermoscopy: presence of whitish-pink areas, surrounded by pinkish-white halos $\left({ }^{*}\right)$, distributed diffusely in "frog-eggs" pattern, associated with a central exulceration (circle) and with a polymorphous vascular pattern (square)

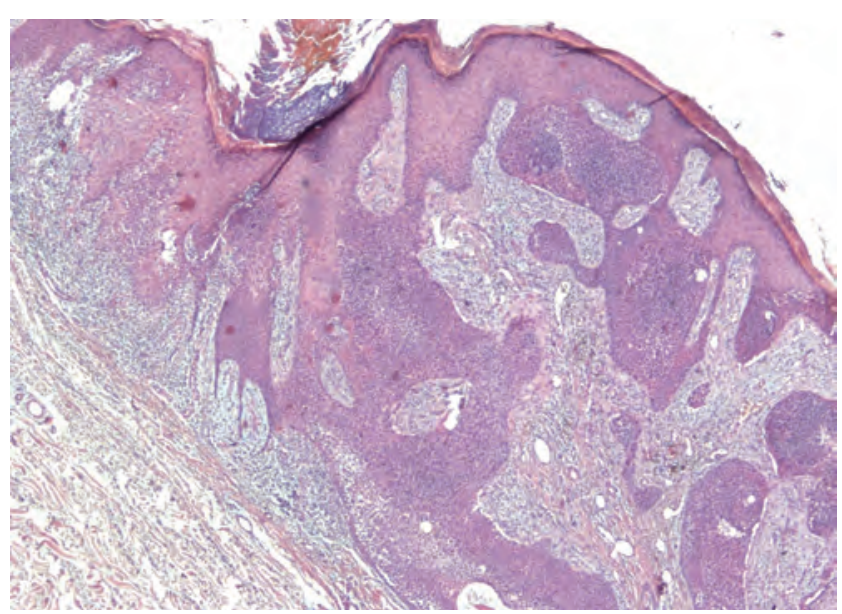

Figure 3: Proliferation of squamous and basal cells, restricted to the epidermis, involving vascular stroma (Hematoxylin \& eosin, x40)

\section{DISCUSSION}

Eccrine porocarcinoma is a rare malignant skin tumor that presumably originates from the intraepidermal duct portion of the eccrine sweat gland. ${ }^{1}$

It was described as a malignant variant of eccrine poroma (EP) in 1963 by Pinkus and Mehregan. ${ }^{2}$

A tumor typically found among older people, the average age at diagnosis is 64 years. Often, the lesions are present for many years before the diagnosis is made, as observed in our case. ${ }^{3}$

The lower limbs are the principal localization of this tumor, corresponding to about half of the cases. ${ }^{4,5}$

At times, EPC presents clinically as a nonspecific lesion, i.e., an erythematous nodule or papule, occasionally with central ulceration. Therefore, its differential diagnoses, in addition to EP, should include seborrheic keratosis, basal cell carcinoma, pyogenic granuloma and amelanotic melanoma. ${ }^{5}$

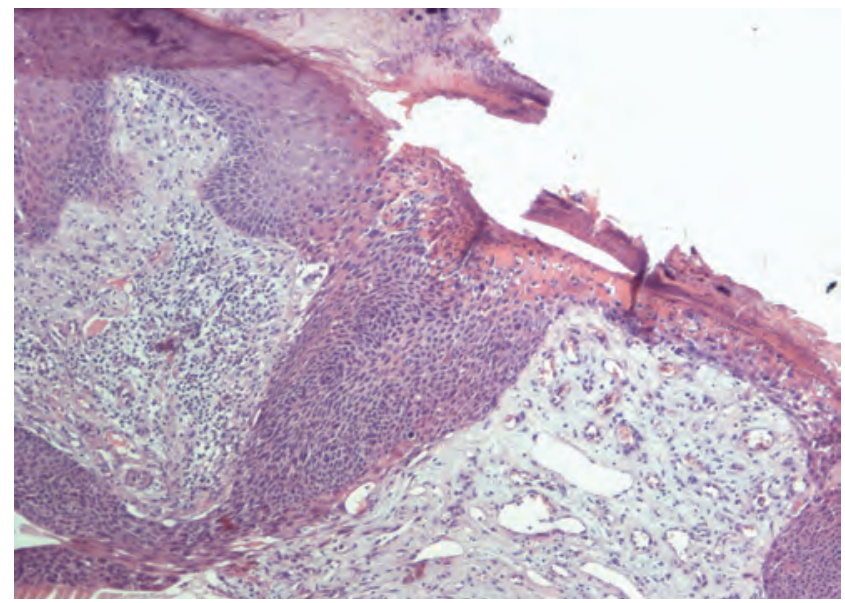

Figure 4: Exulcerated area with hematic crust, as seen in the dermoscopy (Hematoxylin \& eosin, x100)

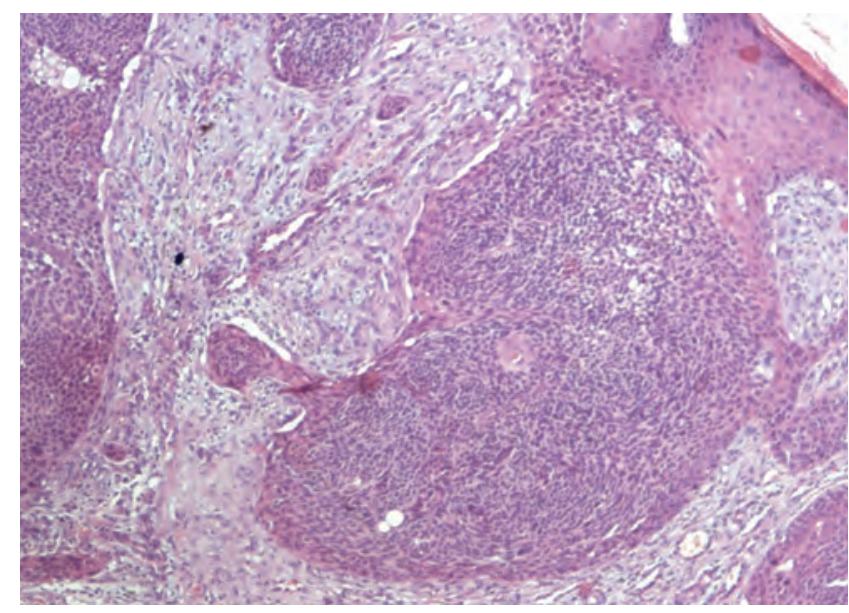

FIGURE 5: Clonal proliferation of basal cells, some with atypia, interspersed with areas of ductal differentiation (Hematoxylin \& eosin, $\mathrm{x} 100)$ 
EPC can arise de novo or from a preexistent EP, though the duration of malignant transformation is highly variable (years to decades). The frequency of this malignancy is still unknown. In this context, porocarcinoma in situ can be considered as a transition from $\mathrm{EP}$ to EPC, due to the presence of residual EP in a variable percentage of EPC in situ viewed in the histopathology. ${ }^{4}$

With respect to the dermoscopic description, Edamitsu et al., in a literature review, analyzed the pattern of eight cases of invasive EPC, concluding that the most common finding was the polymorphous vascular pattern, consisting mainly of hairpin vessels, linear irregular vessels, and dot vessels. However, the authors emphasize the presence of whitish-pink areas surrounded by pinkish-white halos, distributed focally in the lesions. ${ }^{6}$

Minagawa et al., in an analysis of ten cases of EP, concluded that the pinkish-white halos corresponded to a mesh-like proliferation of tumor cells. The whitish-pink, structureless areas are attributed to a richly vascular and edematous stroma beneath a thin epidermis. In these lesions, contrary to what occurs in invasive EPC, such areas present a "frog-eggs" pattern due to their diffuse distribution. ${ }^{7}$
The case described here highlights a transitional pattern between invasive EPC and EP, since we found a diffuse distribution, in a "frog-eggs" pattern, of whitish-pink areas surrounded by pinkish-white halos, associated with a central ulceration and a polymorphous vascular pattern. This finding is consistent with the histopathology of the lesion, which was observed as an EPC in situ originating from a previous EP.

In relation to the clinical characteristics of EPC, studies report that recent alterations, such as bleeding, ulceration and growth of a preexistent poroma, suggest malignant transformation. ${ }^{4}$ In the present report, recent growth was reported by the patient, and central exulceration was found in the clinical exam. The definitive diagnosis is anatomopathological, showing a tumor with eccrine differentiation presenting an invasive architectural pattern or presence of significant cellular pleomorphism. ${ }^{4}$

Finally, we conclude that EPC in situ presents a transitional dermatoscopic pattern between the structures described in EP and invasive EPC, and that the presence of whitish-pink areas surrounded by pinkish-white halos, viewed by dermoscopy, should draw attention to the diagnosis of these conditions.

\section{REFERENCES}

1. Berke A, Grant-Kels JM. Eccrine sweat gland disorders: Part l--Neoplasms. Int J Dermatol. 1994;33:79-85.

2. Pinkus H, Mehregan AH. Epidermotropic Eccrine Carcinoma. A Case Combining Features of Eccrine Poroma and Paget's Dermatosis. Arch Dermatol. 1963:88:597-606.

3. Girishkumar H, Kamineni S, Hwang RR, Levy J, Sadler R. Eccrine porocarcinoma. Dermatol Surg. 1997;23:583-4.

4. Robson A, Greene J, Ansari N, Kim B, Seed PT, McKee PH, et al. Eccrine porocarcinoma (malignant eccrine poroma): a clinicopathologic study of 69 cases. Am J Surg Pathol. 2001;25:710-20.
5. Wittenberg GP, Robertson DB, Solomon AR, Washington CV. Eccrine porocarcinoma treated with Mohs micrographic surgery: A report of five cases. Dermatol Surg. 1999;25:911-3.

6. Edamitsu T, Minagawa A, Koga H, Uhara H, Okuyama R. Eccrine porocarcinoma shares dermoscopic characteristics with eccrine poroma: A report of three cases and review of the published work. J Dermatol. 2016:43:332-5.

7. Minagawa A, Koga H, Takahashi M, Sano K, Okuyama R. Dermoscopic features of nonpigmented eccrine poromas in association with their histopathological features. Br J Dermatol. 2010;163:1264-8.

\footnotetext{
AUTHORS'CONTRIBUTIONS

Juliana Uchiyama $\quad$ (iD) ORCID 0000-0001-8340-7903

Conception and planning of the study; Elaboration and writing of the manuscript; Obtaining, analyzing and interpreting the data; Intellectual participation in propaedeutic and/or therapeutic conduct of the cases studied; Critical review of the literature; Critical review of the manuscript

Márcio Martins Lobo Jardim $\quad$ (iD) ORCID 0000-0002-8431-3607

Approval of the final version of the manuscript; Elaboration and writing of the manuscript; Obtaining, analyzing and interpreting the data; Critical review of the manuscript Neusa Yuriko Sakai Valente $\quad$ (iD) ORCID 0000-0002-8065-2695

Approval of the final version of the manuscript; Conception and planning of the study; Effective participation in research orientation; Participação intelectual em conduta propedêutica e/ ou terapêutica de casos estudados; Critical review of the manuscript

Maria Fernanda Vieira Cunha Camargo $\quad$ (iD) ORCID 0000-0003-2009-1985

Approval of the final version of the manuscript; Intellectual participation in propaedeutic and/or therapeutic conduct of the cases studied; Critical review of the manuscript
}

How to cite this article: Uchiyama J, Jardim MML, Valente NYS, Camargo MFVC. The transition between a poroma and a porocarcinoma evidenced by the dermoscopy. An Bras Dermatol. 2019;94(2):230-2. 